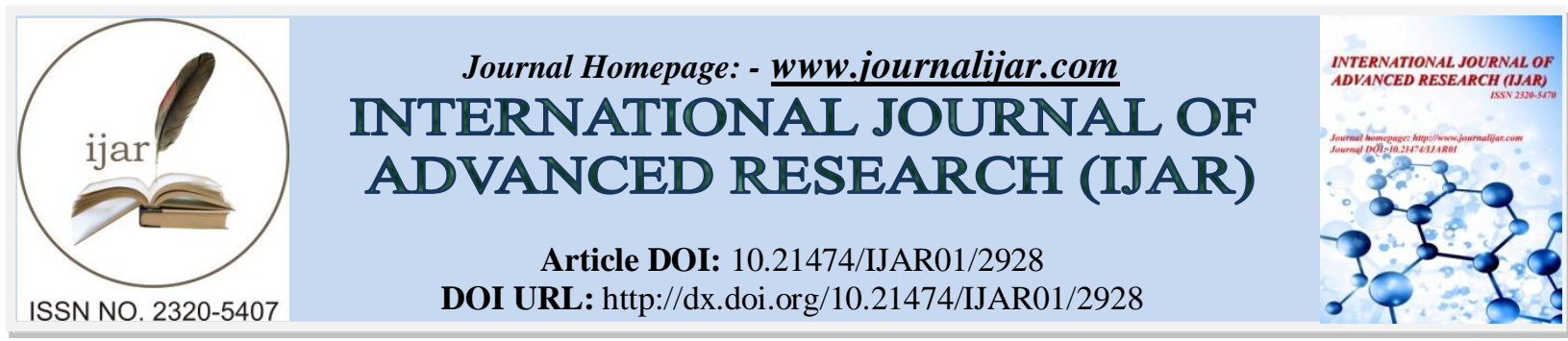

RESEARCH ARTICLE

\title{
A STUDY OF TORSIONAL EFFECT ON MULTI-STORIED BUILDING WITH PLAN- IRRGULARITY.
}

\author{
Subodh. S. Patil, Ajim G Mujawar, Pritam. A. Mali and Murugesh. R. Katti. \\ Asst.Professor, Department of Civil Engineering, ADCET, ASHTA.
}

\section{Manuscript Info \\ Manuscript History \\ Received: 24 November 2016 \\ Final Accepted: 25 December 2016 \\ Published: January 2017}

\section{Key words:-}

Asymmetrical building, Earthquake,

Torsion, Response Spectrum, Remedies

on torsion \&Better solution.

\begin{abstract}
In this paper seismic performance of multistory building is check with asymmetrical plan. At re-entrant corner maximum damage is occur during earthquake. $A \mathrm{G}+20$ and $\mathrm{G}+22$ building having plan Asymmetry is modeled in finite element analysis using STADD-Pro v8i.Accenditial torsional load is applied with reference to 1893(part-1)2002.In this paper we provide architectural relief and providing shear wall at re-entrant corner in the buildings.
\end{abstract}

Copy Right, IJAR, 2016,. All rights reserved.

\section{Introduction:-}

A building should posses four main attributes, namely simple and regular configuration, and adequate lateral strength, stiffness and ductility to perform well in earthquake. Buildings having simple regular geometry and uniformly distributed mass and stiffness in plan as well as in elevation, suffer much less damage than buildings with irregular configurations. But due to architectural consideration we have to construct buildings with irregular according is 1893 clause 7.1 irregular define in two ways plan irregularities and vertical irregularity.

Torsion is caused in building during earthquake due to various reasons, mainly due to non-symmetric mass distribution and stiffness. Torsion is generated in asymmetrical building when the distance between storey's center of rigidity and storey's center of mass is greater than $20 \%$ of the width of the structure in either major plan dimension. In torsion irregularity, inertia force acts through the center of mass while the resistive force acts through the center of rigidity as shown in fig 1 .

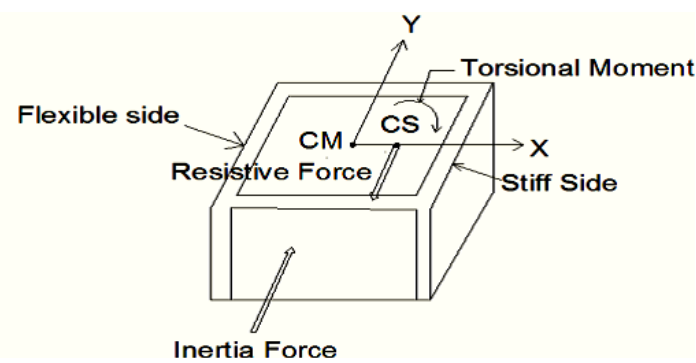

Fig 1:- Generation of torsional moment in asymmetric structures 
The torsion will be developed at Re-entrant corners in L-shape and T- shape Building .the Re-entrant corner, lack of continuity corner is the common characteristic of overall building configuration that in plan .L-shape and T-shape occurs due to lack of tensile capacity and force concentration. According to IS-1893(Part1)-2002, Plan configurations of a structure and its lateral force resisting system contain re-entrant corners, where both projections of the structure beyond the re-entrant corner are greater than 15 percent of its plan dimension in the given direction. In fig 2 shows differential motion between different parts of building, resulting in local stress concentration at the notch of the re-entrant corners.

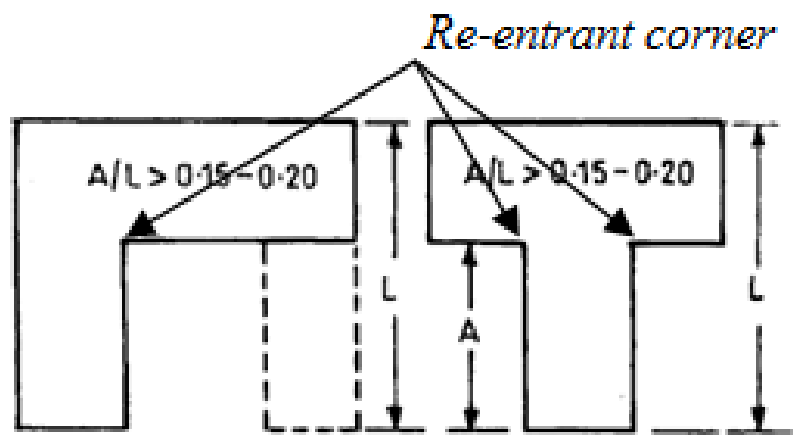

Fig 2:- Examples of building with plan irregularities

There are many remedies to avoid the torsion irregularity are as follows

1. By providing shear wall.

2. By providing uniform box

3. By providing Architectural Relief

4. By providing Diagonal Reinforcement

There are many research carried out on the torsional behavior of building. They give the better solution to avoid the torsion. But they didn't apply it on actual building. In my research paper work, I have applied the solution such as shear wall and architectural relief providing to the building. By analysis I observed that architectural relief is better solution.

\section{Objectivies}

1. To study the torsional effect due to plan irregularity on L-Shape Multi-Storied Building at Re-entrant corner.

2. To study the torsional effect due to plan irregularity on T-Shape Multi-Storied Building at Re-entrant corner.

3. To discuss remedies for torsion irregularities and giving optimize solution for cases as per IS 1893(Part-I)-2002.

\section{Literature Review:-}

1. Mr. Sandesh N. Suryawanshi1, Prof. S. B. Kadam2, Dr. S. N. Tande3(2014)“Torsional Behavior of Asymmetrical Buildings in Plan under Seismic Forces"

In this paper tells us about the torsional behavior of asymmetric building subjected to ground motion using Response Spectrum method.Then he used the non-linear push over analysis has been used to find the structural description.

In this paper the gravity load analysis \& lateral load analysis as per the seismic code IS 1893(part-1):2002 is carried out for three building one is symmetric and other two are asymmetric in plan for variation in building height. Determining the torsional moment, Base shear, displacement \& time period by Response spectrum method \& there capacity \& demand is equivalent using non-linear push over analysis. This paper concluded that time period and base shear calculation by using equivalent static method is approximately equal with response spectrum method in SAP. It also concluded that torsional moment is more in the asymmetry building so beam and column are necessary to design considering torsional moment. The base shear and roof displacement of asymmetry building is more than symmetrical building. By using push over analysis performance of symmetrical building is better than asymmetrical building. 


\section{Prof. Wakchaure M. $\mathbf{R}^{1}$, Nagare Y U ${ }^{2}(2013)$ "Effect of Torsion Consideration in Analysis of Multi Storey} frame"

This paper tells that the study on the influence of the torsion effects on the behavior of structure is done. In this paper two building are considered one is without considering torsion and other is considering the torsion. The building is analyzed and design using method and as per IS1893 (part1):2002.the result are compared in terms \% Ast in column. This paper concluded that In the asymmetric building second building, that is without considering torsion, it was observed that the area of steel in the beams at critical stage are much smaller than those obtained in the case of first building, that is with considering torsion. The bottom bars should be more critical, because they seem to be subjected to more tension than the top bars therefore torsional behavior of asymmetric building is one of the most frequent source of structural damage and failure during strong ground motions. He also concluded that the torsion is the most critical factor causes damage in building, so the irregular buildings are analyzed for torsion.

\section{M.D. Bensalah, M. Bensaibi, A. Modaressi, (2012) "Assessment of the Torsion Effect in Asymmetric Buildings under Seismic Load" \\ This paper studied on the influences of torsional effect on the behavior of the structure. In this paper two buildings are considered one symmetrical and other un-symmetrical building in terms of rigidity. He focused on some parameter such as displacement, ductility, reduction factor and dynamic non accidental eccentricity. This paper concluded that lateral yielding strength in terms of capacity of asymmetric structure is higher than symmetrical structure. The ductility increases with increasing input motion (Arias intensity) and decrease with increasing predominant period with significant variation in asymmetrical structure than those symmetrical structures. The reduction factor decreases when the dominant period of the earthquake increases.}

\section{Methods for Seismic Analysis:-}

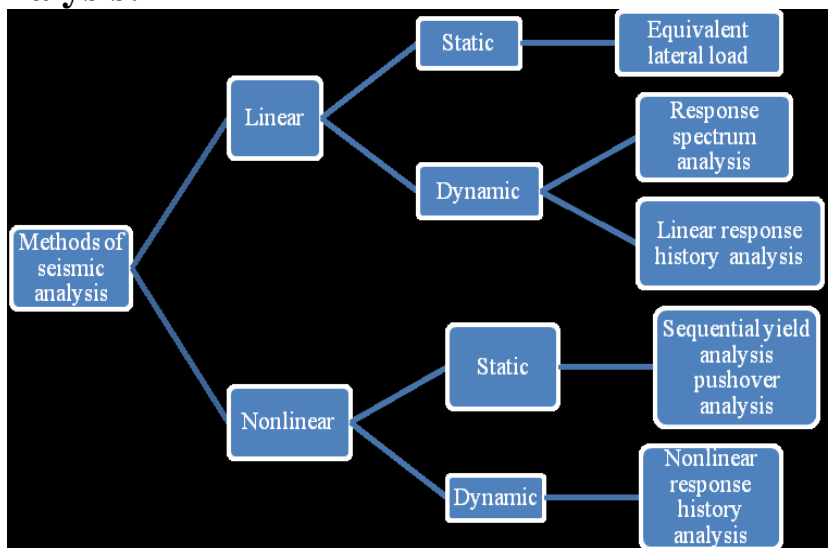

Fig 3:- Methods of seismic analysis

The method of analysis used here is Response Spectrum method and analysis using Stadd-Pro.

\section{Linear static method:-}

The linear static method also known as Equivalent Static Method is used to estimate the demand for the buildings whose response is particularly dominated by the first mode and expected to behave in elastic range. In this method the lateral loads are calculated based on the fundamental period of the structural and applied on the design centre of mass at every floor level and the demands are estimated. The magnitude of these pseudo lateral loads has been selected with the intention that when applied to the linearly elastic model of the building, it will result in design displacement expected during the design earthquake.

If the building responds elastically to the design earthquake, the calculated internal forces will be reasonable approximation of those expected during the design earthquake. If the building Responds in elastically to the design earthquake as is quite common in most of the cases, the actual internal forces that would develop in the yielding building will be less than the internal forces calculated using the pseudo lateral load.

To take these inelasticity account the Response reduction factor (R) is used to calculate the reduced forces. IS1893:2002 uses the empirical formulae to estimate the fundamental time period of the structure. It is used for spectral acceleration determination from the response spectrum, which in turn is used for the calculation of Base 
shear modified by some coefficient. Then this base shear is distributed in the parabolic fashion along the height of building. The effect of the torsion is taken into consideration by calculating the design center of mass by means of design eccentricity.

Design eccentricity is the sum of the actual eccentricity (distance between centre of mass and centre of rigidity at floor level) and accidental eccentricity (5\% of the horizontal dimension at the given floor level measured perpendicular to the direction of the applied load). For two dimensional modeling the design forces are suitably increased to account for torsion.

\section{Linear Dynamic Method:-}

For the building whose response is dominated by more than one mode, the Linear Dynamic Method is used to estimate the demand of the structure. There are two ways to carry out the Linear Dynamic Analysis.

1. Response Spectrum Method

2. Time History Method

\section{Response Spectrum Method:-}

In this method the load vectors are calculated corresponding to predefined number of modes. These load vectors are applied at the design centre of mass to calculate the respective modal responses. These modal responses are then combined according to SRSS or CQC rule to get the total response. From the fundamentals of dynamics it is quite clear that modal response of the structure subjected to particular ground motion, is estimated by the combination of the results of static analysis of the structures subjected to corresponding modal load vector and dynamic analysis of the corresponding single degree of freedom system subjected to same ground motion. Static response of MDOF system is then multiplied with the spectral ordinate obtained from dynamic analysis of SDOF system to get that modal response.

\section{Time History Analysis (Response History Analysis):-}

Dynamic analysis using the time history analysis calculates the building responses at discrete time steps using discredited record of synthetic time history as base motion. If three or more time history analyses are performed, only the maximum responses of the parameter of interest are selected.

\section{Non-linear Static Method:-}

This can be defined as the procedure in which the structure (taking into account the material nonlinearity) is pushed till collapse to generate the pushover curve, which is then used to estimate the target displacement at which the response quantity is extracted from the deformed modal. This is discussed later in detail.

\section{Non-linear Dynamic Analysis:-}

This is the most accurate method to determine the seismic responses of structures. In this method the structure is subjected to actual ground motion which is the representation of the ground acceleration vs. time. The ground acceleration is determined at small time step to give the ground motion record.

Then the structure response is calculated at every time instant, to know its time history and the peak value from this time history is chosen to be the design demand. Hence "a Mathematical model directly incorporating the nonlinear characteristic of individual component and element of the building shall be subjected to earthquake shaking represented by ground by ground motion time history to obtain forces and the displacement"(FEMA 356 \& FEMA 273).

Using Stadd-Pro;-

In the analysis of the building we consider the accidental torsion in Stadd-Pro. In Stadd-Pro uses the Finite Analysis Method.

\section{Building Details:-}

In the present study the seismic load analysis and lateral load analysis as per the seismic code IS 1893 (Part 1): 2002 are carried out. For Two Buildings, one is L-Shape and other T-shape asymmetric in plan for building height G+20 and $\mathrm{G}+22$ for comparison criteria is that numbers of columns are kept same for all three buildings and an effort is made to study the effect of seismic loads on them also determine torsional moments, base shear, displacement and time period by using response spectrum method. 
Problem statement -A G+20 and G+24 storied bare RC Ordinary Moment Resisting Frame has plan as shown in fig. is situated in seismic zone III

A) T-shape Building -

In X-direction-6 Bays of 5m @30m

In Z-direction- 6Bays of 5m @30m

B) L-shape Building

In X-direction-6Bays of 5m @30m

In Z-direction- 8Bays of 5m@40m

Beam size $-0.23 \mathrm{~m} \times 0.45 \mathrm{~m}$

Column size $-0.23 \mathrm{~m} \times 0.45 \mathrm{~m}$

Thickness of slab- $150 \mathrm{~mm}$

Height of storied $-3 \mathrm{~m}$

Plinth height above GL $-1.5 \mathrm{~m}$

Unit weight of concrete $-25 \mathrm{kN} / \mathrm{m} 3$

Live load $-3 \mathrm{kN} / \mathrm{m} 3$

Grade of concrete - M20

Grade of Steel - Fe415
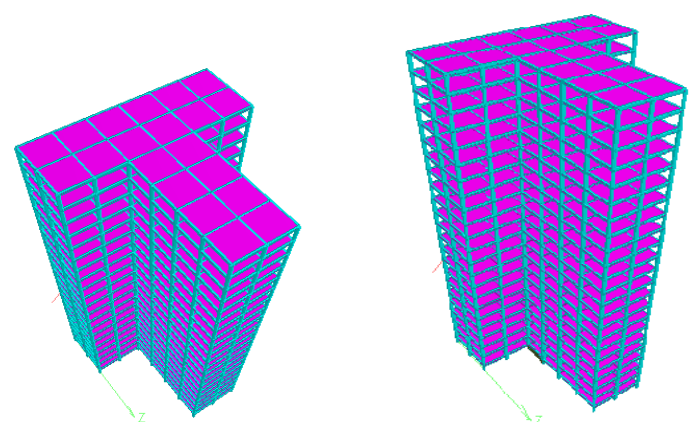

Fig 4:- (a). T-Shape G+20 and G+22 Building without shear wall.
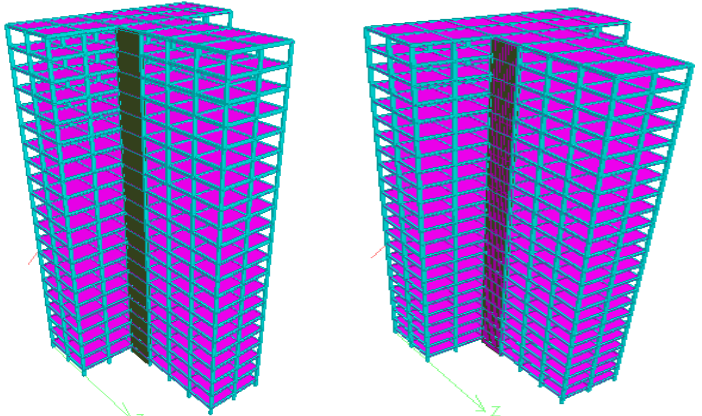

Fig 4:- (b). T-Shape G+20 and G+22 Building with shear wall
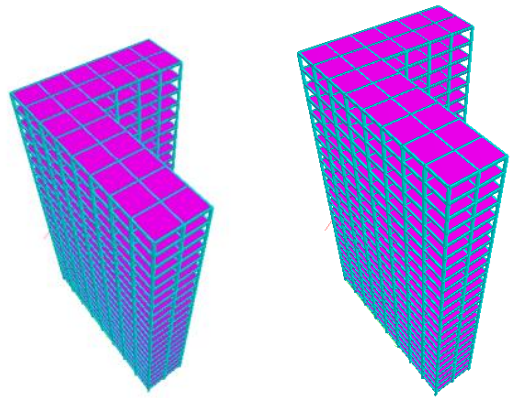

Fig 4:- (c). L-Shape G+20 and G+22 Building 


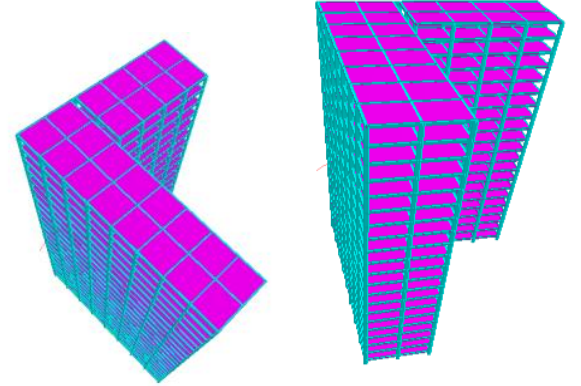

Fig 4:- (d). L-Shape G+20 and G+22 Building with architectural relief

\section{Result and Discussion:-}

Table 1:- (a) Results of L-Shape, G+20 storied building by using STADD-Pro.

\begin{tabular}{|l|l|l|l|}
\hline \multirow{2}{*}{ G+20 Storied building } & \multicolumn{2}{|l|}{$\begin{array}{l}\text { By using software STADDPRO } \\
\text { Response Spectrum Method }\end{array}$} \\
\cline { 2 - 4 } & Seismic weight (KN) & Time Period(Sec) & Base Shear(KN) \\
\hline L-Shape & 66255.94 & 0.87 & 1378.12 \\
\hline $\begin{array}{l}\text { L-Shape with Architectural } \\
\text { Relief }\end{array}$ & 67356.25 & 0.875 & 1394.27 \\
\hline
\end{tabular}

Table 1:- (b) Results of L-Shape, G+20 storied building by using STADD-Pro.

\begin{tabular}{|l|l|l|}
\hline \multirow{2}{*}{ G+20 Storied building } & Displacement(mm) & Torsional Moment (kN-mm) \\
\cline { 2 - 3 } & & \\
\hline L-Shape Architectural & 129.091 & 11226 \\
\hline $\begin{array}{l}\text { L-Shape with } \\
\text { Relief }\end{array}$ & 128 & 7063 \\
\hline
\end{tabular}

Table 2:- (a) Results of L-Shape, G+22 storied building by using STADD-Pro.

\begin{tabular}{|l|l|l|l|}
\hline \multirow{2}{*}{ G+22 Storied building } & By using software STADDPRO \\
\cline { 2 - 4 } & Seismic weight $(\mathrm{KN})$ & Time Period(Sec) & Base Shear(KN) \\
\hline L-Shape & 72579.62 & 0.87 & 1509.65 \\
\hline $\begin{array}{l}\text { L-Shape with Architectural } \\
\text { Relief }\end{array}$ & 73881.18 & 0.875 & 1529.34 \\
\hline
\end{tabular}

Table 2:- (b) Results of L-Shape, G+22 storied building by using STADD-Pro.

\begin{tabular}{|l|l|l|}
\hline G+22 Storied building & Displacement $(\mathrm{mm})$ & Torsional Moment $(\mathrm{kN}-\mathrm{mm})$ \\
\cline { 2 - 3 } & & \\
\hline L-Shape & 165.699 & 11269 \\
\hline L-Shape with Architectural Relief & 164.397 & 7090 \\
\hline
\end{tabular}

Table 3:- (a) Results of T-Shape, G+20 storied building by using STADD-Pro

\begin{tabular}{|l|l|l|l|}
\hline \multirow{2}{*}{ G+20 Storied building } & \multicolumn{3}{|l|}{ By using software STADDPRO } \\
\cline { 2 - 4 } & Seismic weight $(\mathrm{KN})$ & Time Period(Sec) & Base Shear(KN) \\
\hline T-Shape & 55373.61 & 1.01 & 996.72 \\
\hline T-Shape with Shear wall & 58996.92 & 0.84 & 1964.52 \\
\hline
\end{tabular}

Table 3:- (b) Results of T-Shape, G+20 storied building by using STADD-Pro.

\begin{tabular}{|l|l|l|}
\hline \multirow{2}{*}{ G+20 Storied building } & Displacement $(\mathrm{mm})$ & Torsional Moment (KN-mm) \\
\cline { 2 - 3 } & & \\
\hline T-Shape & 81.519 & 5894 \\
\hline T-Shape with Shear wall & 80.959 & 5160 \\
\hline
\end{tabular}


Table 4:- (a) Results of T-Shape, G+22 storied building by using STADD-Pro.

\begin{tabular}{|l|l|l|l|}
\hline \multirow{2}{*}{ G+22 Storied building } & By using software STADDPRO & Base Shear(KN) \\
\cline { 2 - 4 } & Seismic weight (KN) & Time Period(Sec) & 1091.85 \\
\hline T-Shape & 60658.79 & 1.01 & 1163.42 \\
\hline T-Shape with Shear wall & 64634.62 & 1.01 & \\
\hline
\end{tabular}

Table 4:- (b) Results of T-Shape, G+22 storied building by using STADD-Pro.

\begin{tabular}{|l|l|l|}
\hline G+22 Storied building & Displacement $(\mathrm{mm})$ & Torsional Moment $(\mathrm{kN}-\mathrm{mm})$ \\
\hline T-Shape & 99.722 & 6085 \\
\hline T-Shape with Shear wall & 96.363 & 5669 \\
\hline
\end{tabular}

Table 5:- (a) Results of L-Shape, G+24 storied building by using STADD-Pro.

\begin{tabular}{|l|l|l|l|}
\hline \multirow{2}{*}{ G+24 Storied building } & \multicolumn{2}{|l|}{ By using software STADDPRO } & Base Shear(KN) \\
\cline { 2 - 4 } & Seismic weight (KN) & Time Period(Sec) & 1641.18 \\
\hline L-Shape & 78903.3 & 0.87 & 1664.62 \\
\hline $\begin{array}{l}\text { L-Shape with Architectural } \\
\text { Releif }\end{array}$ & 80416.73 & 0.875 & \\
\hline
\end{tabular}

Table 5:- (b) Results of L-Shape, G+24 storied building by using STADD-Pro.

\begin{tabular}{|l|l|l|}
\hline G+24 Storied building & Displacement(mm) & Torsional Moment (KN-mm) \\
\cline { 2 - 2 } & & \\
\hline L-Shape & 202.318 & 11630 \\
\hline $\begin{array}{l}\text { L-Shape with Architectural } \\
\text { Relief }\end{array}$ & 200 & 7511 \\
\hline
\end{tabular}

Table 6:- (a) Results of T-Shape, G+24 storied building by using STADD-Pro.

\begin{tabular}{|c|c|c|c|}
\hline \multirow[t]{2}{*}{$\mathrm{G}+24$ Storied building } & \multicolumn{3}{|c|}{ By using software STADDPRO } \\
\hline & Seismic weight $(\mathrm{KN})$ & Time Period $(\mathrm{Sec})$ & Base Shear(KN) \\
\hline T-Shape & 65943.96 & 1.01 & 1186.99 \\
\hline T-Shape with Shear wall & 70273.41 & 0.875 & 1264.92 \\
\hline
\end{tabular}

Table 6:- (b) Results of T-Shape, G+24 storied building by using STADD-Pro.

\begin{tabular}{|l|l|l|}
\hline \multirow{2}{*}{ G+24 Storied building } & Displacement $(\mathrm{mm})$ & Torsional Moment (kN-mm) \\
\cline { 2 - 2 } & & \\
\hline T-Shape & 124.22 & 6105 \\
\hline T-Shape with Shear wall & 123 & 5804 \\
\hline
\end{tabular}

\section{Discussion:-}

1) As the height of L-shape building increases, there is increases in the base shear by $9.54 \%$ from the results tabulated in table 5(a) \&6(a).

2) The torsional moment in L- Shape building decreases using architectural relief by $37 \%$ from results tabulated in table 1(b).

\section{Conclusions:-}

In this paper modeling of multistoried building with plan irregularity is done. In accordance with IS1893-2002 for simulation purpose finite element analysis STADD-Pro V $8 \mathrm{i}$ is used following conclusions are formed after studying T-shape and L-shape Building with variation of height.

1) Increase in height of L-shape building directly increase in relative displacement \& stress at re-entrant corners

2) Architectural Relief is given for L-Shape building relatively considerable decrease in displacement and also decrease in stresses at re-entrant corners. 
3) Increase in height of T-shape building directly increase in relative displacement and stress will be developed at re-entrant corner.

4) A T-shape building with shear wall and without shear wall is analyzed and it is observed that nodal displacement and beam displacement reduced comparatively but stresses at re-entrant corners does not vary

5) In T- shape building shear wall must be provided at re-entrant corners only

6) Architectural Relief is the better solution on the re-entrant corner on which maximum earthquake damage is done.

7) The torsional moment in symmetrical building is very less as compared with unsymmetrical building.

\section{References:-}

1. Mr. Sandesh N. Suryawanshi1, Prof. S. B. Kadam2, Dr. S. N. Tande3,(2014), Torsional Behaviour of Asymmetrical Buildings in Plan under Seismic Forces, Volume 2, 170-176

2. Dr. B. G. Naresh Kumar, Avinash Gornale and Abdullah Mubashir "Seismic Performance Evaluation of R cFramed Buildings - An Approach to Torsionally Asymmetric Buildings" IOSR Journal of Engineering (IOSRJEN) ISSN: 2250-3021 Volume 2, Issue 7(July 2012), PP 01-12

3. Mahdi \& V. Soltangharaie "Static and Dynamic Analyses of Asymmetric Reinforced Concrete Frames" 15 WCEE, LISBOA 2012

4. Sachin G. Maske, Dr. P. S. Pajgade "Torsional Behaviour of Asymmetrical Building" International Journal of Modern Engineering Research (IJMER) www.ijmer.com Vol.3, Issue.2, March-April. 2013 pp-1146-1149 ISSN: 2249-664

5. IS:1893(Part-1):2002 Criteria for earth quake resistant design of structure, 